\title{
Non-anesthesiologist-administered propofol: where do we stand?
}

\section{(2) $\circledast \Theta$}

\author{
Author \\ Jean-Marc Dumonceau \\ Institution \\ Gedyt Endoscopy Center, Buenos Aires, Argentina \\ Bibliography \\ DOI https://doi.org/10.1055/a-0832-1967 | \\ Endoscopy International Open 2019; 07: E630-E632 \\ (c) Georg Thieme Verlag KG Stuttgart · New York \\ ISSN 2364-3722
}

The safety and efficacy of propofol administered by trained non-anesthesiologists to low-risk patients has been demonstrated ad nauseum. Most recently, a prospective study assessed all consecutive endoscopic procedures performed in 39 German centers, 314,190 and 40,280 procedures with and without sedation, respectively [1]. An anesthesiologist was present in $0.2 \%$ of the cases. Minor sedation-related adverse events $(A E)(0.3 \%)$ and deaths $(0.005 \%)$ were rare. Interestingly, sedation-related AEs were less frequent with propofol vs. midazolam (odds ratio, 0.75; $95 \%$ confidence interval, 0.58 $0.97)$. Safety and efficacy have been suggested to be similar if propofol is administered by anesthesiologists vs. non-anesthesiologists for upper or lower gastrointestinal) endoscopy in patients with an American Society of Anesthesiologists (ASA) classification of I or II according to a meta-analysis (5 studies, 21,054 patients) [2]. Non-anesthesiologist-administered propofol (NAAP) is also cost-effective: for colorectal cancer screening, it has been calculated that the mortality rate of NAAP would have to increase by 31 -fold or the costs of anesthesia be reduced by 17 -fold for anesthesiologist-assisted procedures to be as cost-effective as NAAP [3].

In this issue of Endoscopy International Open, Patel et al. report on the safety and outcomes of NAAP for upper gastrointestinal endoscopy in a riskier group of patients: those admitted to the intensive care unit (ICU) for management of gastrointestinal bleeding [4]. Procedures were successfully completed in $91 \%$ of patients; blood oxygen desaturation (<90\%) was reported in a proportion of patients similar to previous studies $(7.5 \%$ vs. $5.4 \%-11.0 \%$ ) while hypotension (systolic blood pressure $<90 \mathrm{~mm} \mathrm{Hg}$ ) was much more frequent $(23.0 \%$ vs. $2.8 \%-12.5 \%$ of patients), likely reflecting the underlying volume depletion in gastrointestinal bleeders. Performance of endoscopic treatment in the ICU is desirable for critically ill pa- tients as intrahospital patient transportation remains associated with a very high incidence of AEs [5]. Therefore, an adequately equipped mobile endoscopy cart is available in most hospitals and, as safety conditions in the ICU are ideal, performing endoscopic therapy there under NAAP is very welcome.

Apart from its retrospective design, the study is limited by the absence of follow-up and of a modern score specific to upper gastrointestinal bleeding. Patient admission to the ICU does not attest to bleeding severity; an endoscopic intervention was performed in only $11 \%$ of patients and endoscopy duration was relatively short at $16 \pm 11$ minutes, both criteria suggesting that not all patients were severely ill. On the other hand, scores like the AIMS65 and the Glasgow-Blatchford score perform well to predict relevant outcomes, including in-hospital mortality [6].

As experience with NAAP continues to expand, further studies are expected in selected risky patient groups (e.g., ASA class $\geq 3$ ) as well as for complex and long procedures. Other points that need to be addressed in future studies include the necessity to have a person dedicated exclusively to NAAP during the procedure, monitoring devices, training, new modes of propofol administration, and use of other drugs.

The necessity or not of an additional person solely dedicated to NAAP is key because of cost issues. It was amply debated in 2015 during the update of the Guideline about NAAP by the European Society of Gastrointestinal Endoscopy [7]. After a tie vote, safety was privileged and presence of an additional person dedicated to NAAP was recommended. However, in the large study mentioned above, no additional person dedicated to NAAP was present in approximately half of the cases and there were fewer complications when no additional person was present [1]. Until studies specifically analyze this issue, it will remain unresolved. 
Capnography allows detection of respiratory compromise earlier than does pulse oximetry but no clinically relevant benefits for patients have been demonstrated. Furthermore, it is costly and it may be impractical because of false-positive alarms that cause fatigue to relevant alarms [8]. For these reasons, capnography's use has been suggested by endoscopy societies only in selected situations [7]. Various manufacturersupported publications have recently tried to promote its universal use, including during moderate sedation. Using a model, Saunders et al. calculated that routine use of capnography indeed reduces costs, even for moderate sedation [9]. However, the model was flawed. For example, for moderate sedation in ASA class I and II patients, blood oxygen desaturation was assumed to develop in $25.2 \%$ of patients not monitored with capnography. Then, one-third of these patients would require positive pressure ventilation at a cost of \$ 604 USD. The $25.2 \%$ figure was inexplicably extracted from a low-quality retrospective study, not of endoscopy but of enteroclysis [10]. In that study, sedation depth was not reported, basal oxygen was not administered, sedated patients were transported to other rooms and, to treat oxygen desaturation, no positive pressure ventilation was used (oxygen was administered). Capnography is a valuable tool but the issues of costs, including that of disposable material, and practicality should be addressed by manufacturers.

The quality of endoscopic sedation has recently been questioned in various surveys [11]: in Europe, only one-third of individuals administering sedation would have followed theoretical and practical sedation courses and a data registration system for AEs would be absent in $60 \%$ of the centers. These results were collected from only 33 representatives of anesthesiologists and nurse anesthetists but they are backed by other surveys: in the UK, $51 \%$ of 78 gastroenterology trainees had not received a structured training in sedation [12] while in Korea $27 \%$ of 1332 endoscopists were performing sedation (mostly using propofol) with no specific training [13]. Curricula have been published to help design sedation training courses; they suggest, apart from didactic courses, the use of simulators, observation and finally performance of sedation under supervision [14]. Such training programs are effective [15] and tools for assessing competence in NAAP have been validated [16] but structured sedation courses must be made available more widely.

A mode of propofol administration that has attracted little interest up to now is patient-controlled sedation (PCS). With PCS, a pump delivers drugs intravenously when the patient presses a button. Propofol-based PCS was associated with a lower risk of rescue interventions to treat sedation-related AEs and it provided similar operator and patient satisfaction compared with clinician-controlled sedation in a meta-analysis (13 randomized controlled trials [RCTs], 1103 patients) [17]. The acceptability of the technique by patients, who must be willing to take the responsibility of sedation, has limited its adoption up to now but technological developments may further improve the safety and acceptability of PCS.
Finally, propofol is unlikely to be dethroned but other drugs with a supposed better security profile may be useful, particularly in high-risk patients.

- Etomidate, a short-acting hypnotic drug commercialized 15 years before propofol, is being rediscovered. This drug is mostly used by anesthesiologists for rapid sequence intubation and it is known for its minimal effect on cardiovascular parameters. Etomidate-based sedation was associated with a lower risk of hypoxemia and apnea, similar recovery time and similar patient satisfaction compared with propofolbased regimens for endoscopy in a meta-analysis (6 RCTs, 1115 patients) [18].

- Dexmedetomidine, a mild sedative with analgesic properties and few cardiorespiratory effects, has recently been approved for endoscopic sedation in some countries. It is commonly used in the ICU but, for endoscopy, a meta-analysis (6 RCTs, 361 patients) reported lower patient satisfaction compared with propofol [19]. The high cost and the requirement for a lengthy initial infusion are other drawbacks of dexmedetomidine.

Endoscopic sedation has come a long way since an audit in England has shown high complication rates associated with poor sedation practices that were common in the 1990 s [20]. Introduction of NAAP, and the resistance it has generated in some anesthesiology communities, has indeed contributed to this improvement. With the help of anesthesiologists, we will build on the current momentum to improve quality and continue to find creative solutions to better serve our patients in a world of limited resources.

\section{Competing interests}

None

\section{References}

[1] Behrens A, Kreuzmayr A, Manner $\mathrm{H}$ et al. Acute sedation-associated complications in gastrointestinal endoscopy (ProSed 2 Study): results from the prospective multicentre electronic registry of sedationassociated complications. Gut 2018: gutjnl-2015-311037 doi:10.1136/gutjnl-2015-311037

[2] Daza JF, Tan CM, Fielding RJ et al. Propofol administration by endoscopists versus anesthesiologists in gastrointestinal endoscopy: a systematic review and meta-analysis of patient safety outcomes. Can J Surg 2018; 61: $226-236$

[3] Hassan C, Rex DK, Cooper GS et al. Endoscopist-directed propofol administration versus anesthesiologist assistance for colorectal cancer screening: a cost-effectiveness analysis. Endoscopy 2012; 44: $456-464$

[4] Patel J, Fang J, Taylor L et al. Safety and efficacy of non-anesthesiologist administration of propofol sedation during esophagogastroduodenoscopy in the intensive care unit. Endosc Int Open 2019; 07: E625-E629

[5] Jia L, Wang H, Gao Y et al. High incidence of adverse events during intra-hospital transport of critically ill patients and new related risk 
factors: a prospective, multicenter study in China. Critical Care 2016; 20: 12

[6] Cai JX, Saltzman JR. Initial assessment, risk stratification, and early management of acute nonvariceal upper gastrointestinal hemorrhage. Gastrointest Endosc Clin N Am 2018; 28: 261-275

[7] Dumonceau J-M, Riphaus A, Schreiber F et al. Non-anesthesiologist administration of propofol for gastrointestinal endoscopy: European Society of Gastrointestinal Endoscopy, European Society of Gastroenterology and Endoscopy Nurses and Associates Guideline - Updated June 2015. Endoscopy 2015; 47: 1175-1189

[8] Klare P, Reiter J, Meining A et al. Capnographic monitoring of midazolam and propofol sedation during ERCP: a randomized controlled study (EndoBreath Study). Endoscopy 2016; 48: 42-50

[9] Saunders R, Erslon M, Vargo J. Modeling the costs and benefits of capnography monitoring during procedural sedation for gastrointestinal endoscopy. Endosc Int Open 2016; 4: E340-351

[10] Maglinte DDT, Applegate KE, Rajesh A et al. Conscious sedation for patients undergoing enteroclysis: Comparing the safety and patientreported effectiveness of two protocols. Eur J Radiol 2009; 70: $512-$ 516

[11] Vaessen HHB, Knape JTA. Considerable variability of procedural sedation and analgesia practices for gastrointestinal endoscopic procedures in Europe. Clin Endosc 2016; 49: 47 - 55

[12] Mohanaruban A, Bryce K, Radhakrishnan A et al. Safe sedation practices among gastroenterology registrars: do we need more training. Frontline Gastroenterol 2015; 6: 223 - 228

[13] Lee CK, Dong SH, Kim ES et al. Room for quality improvement in endoscopist-directed sedation: results from the first nationwide survey in Korea. Gut and Liver 2016; 10: $83-94$
[14] Dumonceau JM, Riphaus A, Beilenhoff U et al. European curriculum for sedation training in gastrointestinal endoscopy: position statement of the European Society of Gastrointestinal Endoscopy (ESGE) and European Society of Gastroenterology and Endoscopy Nurses and Associates (ESGENA). Endoscopy 2013; 45: 496 - 504

[15] Jensen JT, Vilmann P, Horsted T et al. Nurse-administered propofol sedation for endoscopy: a risk analysis during an implementation phase. Endoscopy 2011; 43: 716-722

[16] Jensen JT, Savran MM, Møller AM et al. Development and validation of a theoretical test in non-anaesthesiologist-administered propofol sedation for gastrointestinal endoscopy. Scand J Gastroenterol 2016; 51: $872-879$

[17] Kreienbühl L, Elia N, Pfeil-Beun E et al. Patient-controlled versus clinician-controlled sedation with propofol: systematic review and metaanalysis with trial sequential analyses. Anesthesia Analgesia 2018; 127: $873-880$

[18] Ye L, Xiao X, Zhu L. The comparison of etomidate and propofol anesthesia in patients undergoing gastrointestinal endoscopy: a systematic review and meta-analysis. Surg Laparosc Endosc Percutan Tech 2017; 27: $1-7$

[19] Nishizawa T, Suzuki H, Hosoe $\mathrm{N}$ et al. Dexmedetomidine vs propofol for gastrointestinal endoscopy: A meta-analysis. United European Gastroenterol J 2017; 5: 1037-1045

[20] Quine MA, Bell GD, McCloy RF et al. Prospective audit of upper gastrointestinal endoscopy in two regions of England: safety, staffing, and sedation methods. Gut 1995; 36: 462-467 